\title{
Hemorrhagic Diathesis in Weber-Christian Disease
}

\author{
Kazuo Mori, Iwao Hiratsuka, Hideaki Sakai, Katsuhide \\ Hiwatashi, Tsuneo Takahashi, Yoshisuke Maruhama and \\ Shoichi Yamagata \\ Department of Internal Medicine, Tohoku University School \\ of Medicine, Sendai
}

\begin{abstract}
Mori, K., Hiratsuka, I., Sakai, H., Hrwatashi, K., Takahashi, T., Maruhama, Y. and Yamagata, S. Hemorrhagic Diathesis in Weber-Christian Disease. Tohoku J. exp. Med., 1976, 118 (Suppl.), 227-243 — A case of a 21. year-old woman with Weber-Christian disease, associated with consumption coagulopathy and adequately controlled over the past year or more by corticosteroid and heparin therapy, has been described. Through the study on this case, it was concluded that a hemorrhagic diathesis complicating Weber-Christian disease, at least in advanced cases, was characterized by consumption coagulopathy associated with enhanced blood coagulability which arises from hyperlipemia due to abnormal lipid metabolism and further, that the consumption coagulopathy was modified by diminished synthesis of clotting factors and activation of the fibrinolytic system due to the secondary hepatic impairment. It might also be likely that systemic vascular changes contribute to the activation of the clotting system as a trigger of clotting factor consumption. The complex pathophysiology of a hemorrhagic diathesis in this disease seemed to be brought about by a complex combination of such a variety of factors. In addition, decreased erythrocyte sedimentation rate observed characteristically during hemorrhage might probably have a direct correlation with hypofibrinogenemia due to consumption coagulopathy in advanced cases. - Weber-Christian disease; hemorrhagic diathesis; hyperlipemia; vascular change; consumption coagulopathy
\end{abstract}

Weber-Christian disease is a relatively rare disease of unknown cause characterized primarily by a systemic lipolysis of the adipose tissues of the whole body. The present paper deals with a case of this disease in which prominent hemorrhagic manifestations developed with findings of altered blood coagulability leading to a diagnosis of consumption coagulopathy (or intravascular coagulation syndrome). The relationship between hemorrhagic diathesis and this disease is discussed.

\section{Peport of Case}

\section{Patient: A 21-year-old woman.}

A few years prior to the first visit, the patient had begun having attacks of fever of about $39^{\circ} \mathrm{C}$ around January and February and received medical treatment with complete relief on each occasion. On February 7, 1972, she was examined

Received for publication, November 20, 1975 . 
because of a progressively enlarging, palm-sized, painful, subcutaneous induration with redness and swelling on the medial surface of the right thigh for which treatment including chemotherapy and incision was given with no significant relief. From about February 11, she continuously ran a fever of $39^{\circ} \mathrm{C}$ or higher, and showed an increase of the involvement over the thigh on about February 21. The patient was admitted to the dermatological ward of this hospital on February 28.

Dermatological findings on admission (Fig. 1). A palm-sized subcutaneous induration with redness and swelling was noted on the medial surface of the right thigh. The induration was markedly tender and there was an old incision in the center of the lesion. Several painful nodules ranging up to the size of a thumb were

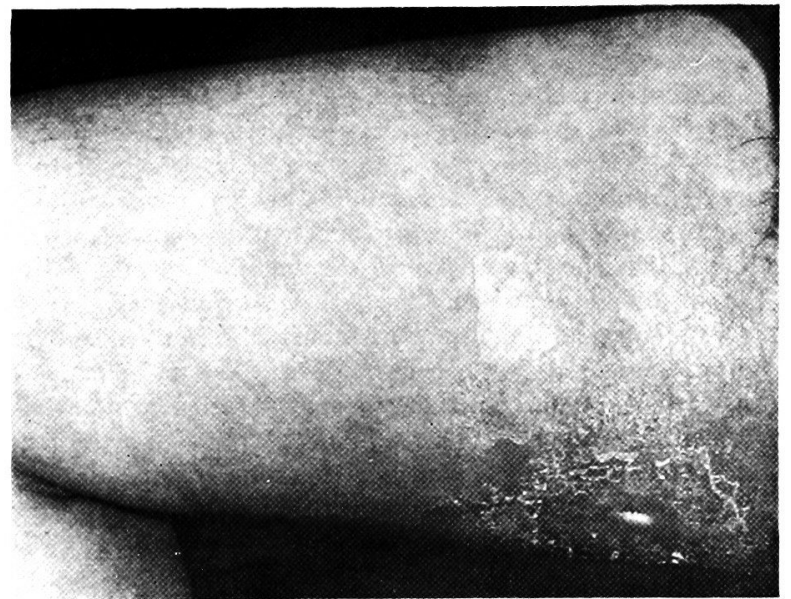

Fig. 1. Subcutaneous induration on the medial surface of the right thigh.

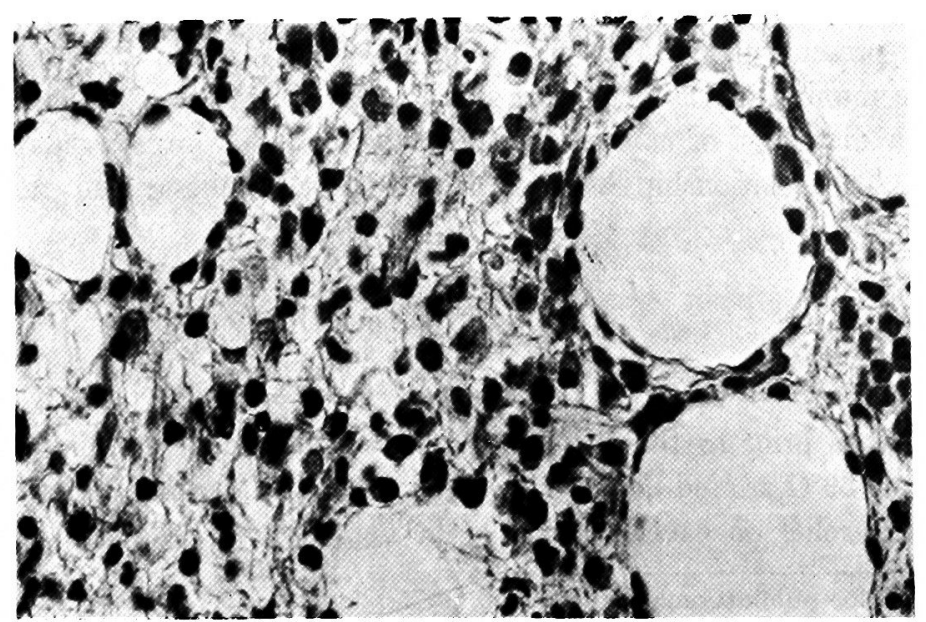

Fig. 2. Histological findings. 
also noted intradermally or subcutaneously over the left thigh as well as the right thigh. From these dermatologic findings, a tentative diagnosis of Weber-Christian disease was made.

Histological findings (Fig. 2). The diagnosis of Weber-Christian disease was confirmed on the grounds of histopathological findings of prominent cellular infiltration into subcutaneous fat tissues primarily with neutrophils and histiocytes.

Laboratory findings on admission to the dermatological ward (Table 1). The erythrocyte sedimentation rate was increased, being $62 \mathrm{~mm}$ in $1 \mathrm{hr}$ and $97 \mathrm{~mm}$ in

TABLE 1. Laboratory examinations on admission to the dermatological ward

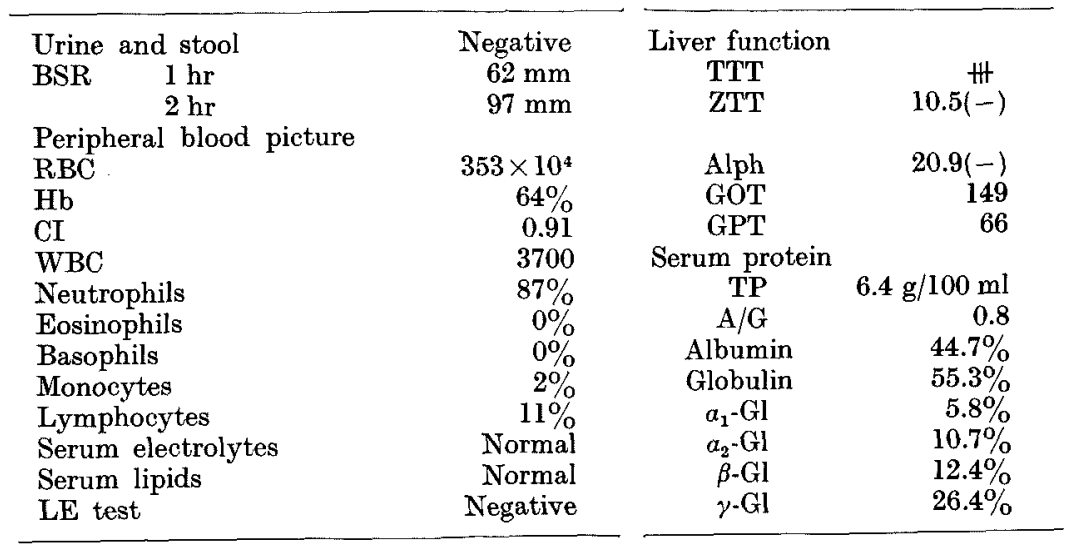

TABLE 2. Laboratory examinations on transfer to our department

\begin{tabular}{|c|c|c|c|}
\hline Urine & \multicolumn{3}{|c|}{ Liver function } \\
\hline Protein & + & & \\
\hline Sugar & + & TTT & $9.7(+)$ \\
\hline Urobilinogen & + & ZTT & $9.3(-)$ \\
\hline Microscopy & Normal & I.I. & \\
\hline Stool & Negative & Alph & 9.6 \\
\hline $\begin{array}{l}\text { BSR } 1 \mathrm{hr} \\
2 \mathrm{hr}\end{array}$ & $1 \mathrm{~mm}$ & GOT & $\begin{array}{l}59 \\
43\end{array}$ \\
\hline Peripheral blood picture & $3 \mathrm{~mm}$ & Serum protein & \\
\hline RBC & $432 \times 10^{4}$ & TP & $6.4 \mathrm{~g} / 100 \mathrm{ml}$ \\
\hline $\mathrm{Hb}$ & $90 \%$ & $\mathrm{~A} / \mathrm{G}$ & 1.3 \\
\hline CI & 1.06 & Albumin & $56.8 \%$ \\
\hline WBC & 2525 & Globulin & $43.2 \%$ \\
\hline Platelet count & $14.6 \times 10^{4}$ & $a_{1}-\mathrm{Gl}$ & $6.3 \%$ \\
\hline Reticulocytes & $2.1 \%$ & $a_{2}-G l$ & $7.5 \%$ \\
\hline Neutrophils & $71 \%$ & $\beta-\mathrm{Gl}$ & $10.0 \%$ \\
\hline Eosinophils & $0 \%$ & $\gamma$-Gl & $19.4 \%$ \\
\hline Basophils & $0 \%$ & Serum lipids & \\
\hline Monocytes & $11 \%$ & Triglyceride & $160 \mathrm{mg} / 100 \mathrm{ml}$ \\
\hline Lymphocytes & $17 \%$ & Phospholipid & 320 \\
\hline Serum electrolytes & & Total cholesterc & 320 \\
\hline $\mathbf{K}$ & $4.6 \mathrm{mg} / 100 \mathrm{ml}$ & Red cell fragmen & ntiaton $13 \%$ \\
\hline $\mathrm{Ca}$ & 4.6 & & \\
\hline $\mathrm{Na}$ & 141 & & \\
\hline $\mathrm{Cl}$ & 97 & & \\
\hline
\end{tabular}



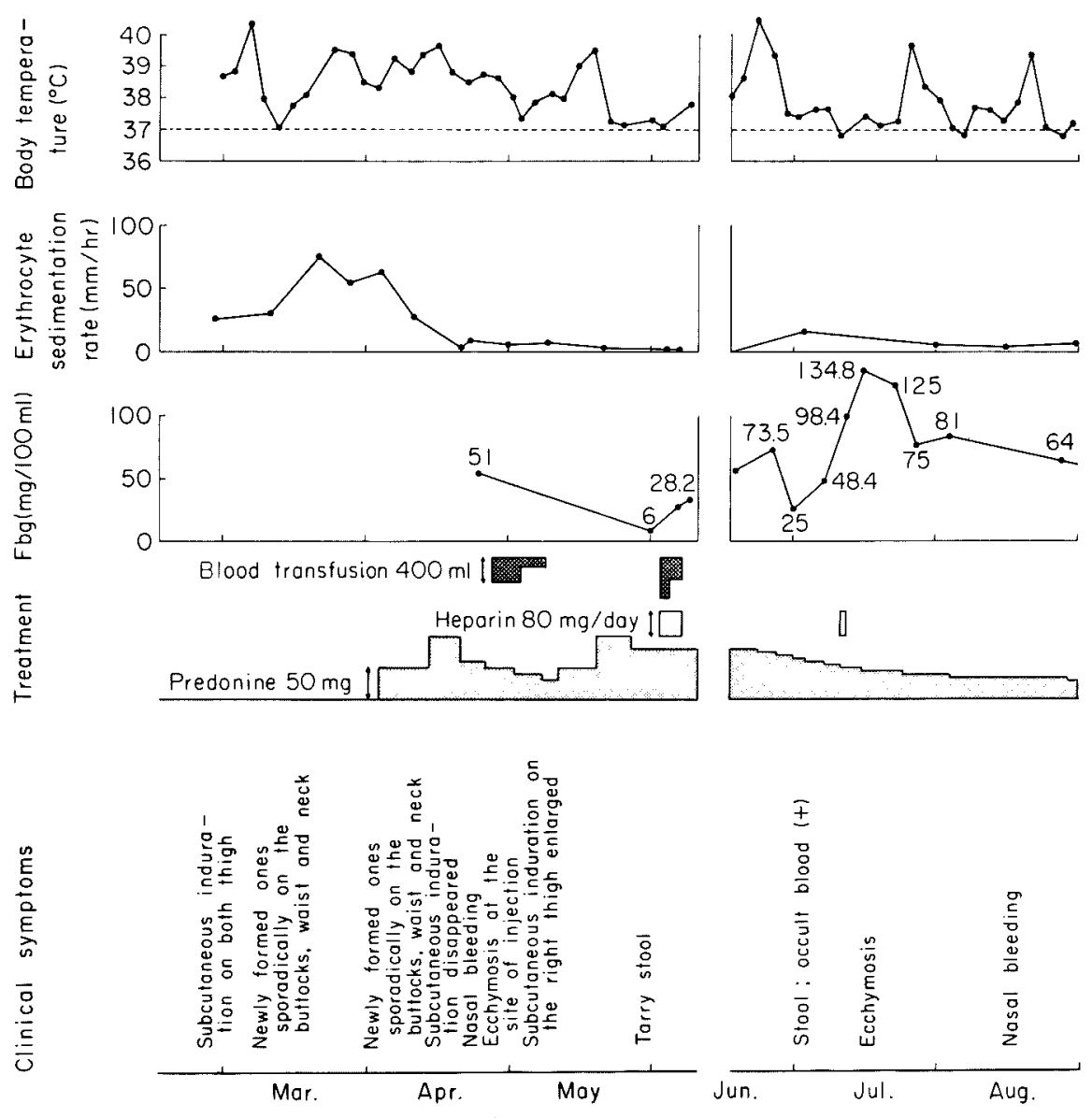

Fig. 3. Clinical course (1).

$2 \mathrm{hr}$, and liver function tests were slightly impaired. Hematological examination showed a mild anemia with leukopenia.

Laboratory findings on transfer to our department (Table 2). Laboratory studies at that time revealed positive urinary protein and sugar with an unremarkable sediment and a markedly decreased blood sedimentation rate. The hepatic function tests almost completely improved, while a slight degree of hyperlipemia was noted. Hematological examinations showed an apparent improvement in anemia due to blood transfusions, but still leukopenia, slight thrombocytopenia, and erythrocyte fragmentation were noted.

Clinical course (Figs. 3 and 4). There were numerous subcutaneous indurations and nodules distributed primarily on both thighs and additionally, newly formed ones sporadically on the buttocks, waist and right side of the neck (in March through April). Fever $\left(39^{\circ}\right.$ to $40^{\circ}$ ) was persistent and the erythrocyte sedimentation rate was increased. And then, a variety of antibiotics and antipyretics were 


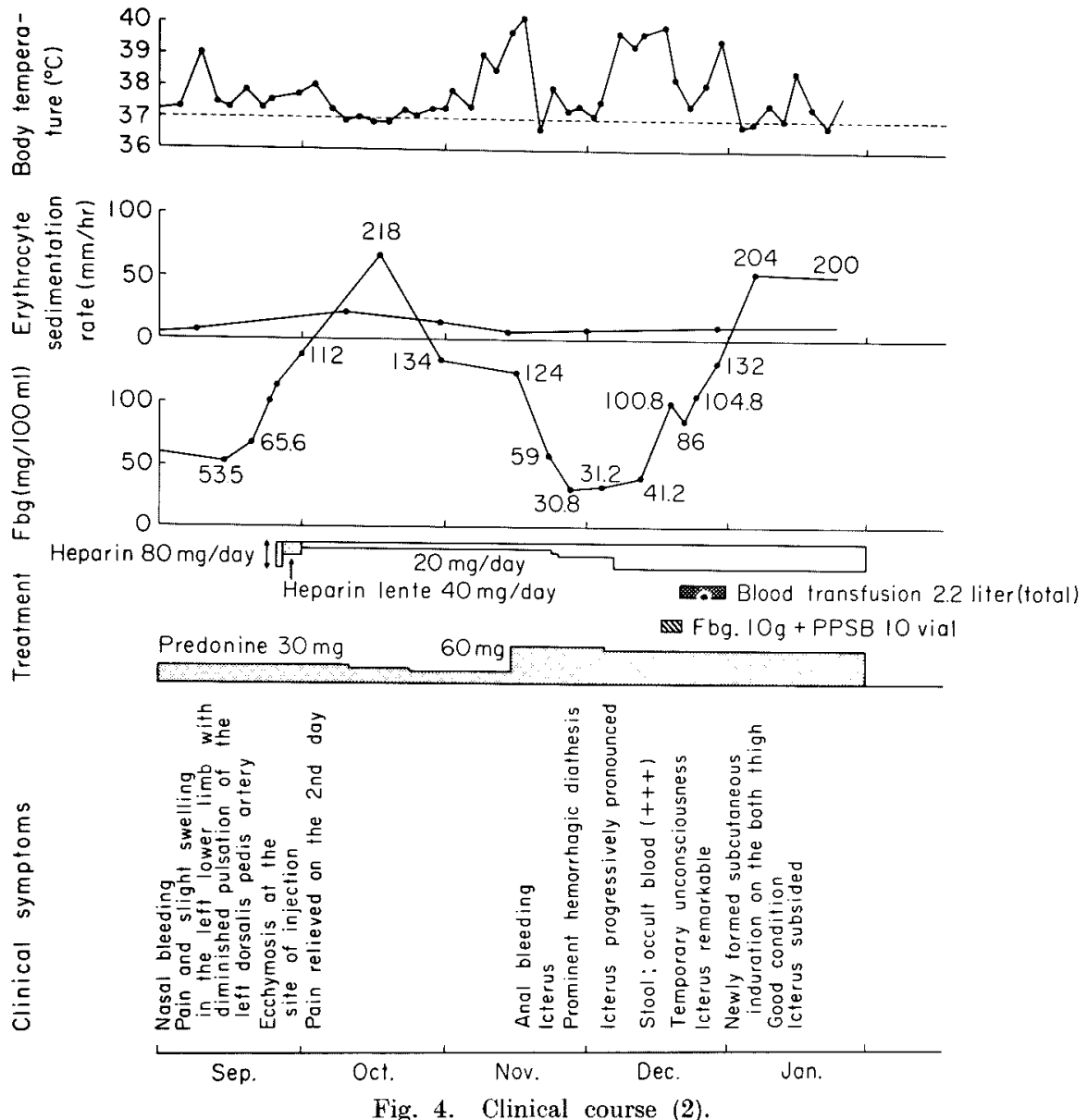

given. She was put on predonisolone, $50 \mathrm{mg} /$ day, in April with subsequent dosage increase to $100 \mathrm{mg} /$ day. She remained febrile, and, on April 21, had an episode of epistaxis and was noted to develop easily subcutaneous ecchymosis at the sites of injections. There was then an extreme improvement of the erythrocyte sedimentation rate to $2 \mathrm{~mm} / \mathrm{hr}$, contrary to the manifestations of the inflammatory reaction, fever, and general conditions. Hematological examinations at that time revealed thrombocytopenia $\left(2.7 \times 10^{4} / \mathrm{mm}^{3}\right.$ on April 25 , and $4.1 \times 10^{3} / \mathrm{mm}^{3}$ on May 1); and a blood coagulation test showed a plasma fibrinogen ( $\mathrm{Fbg}$ ) level of $51 \mathrm{mg} /$ $100 \mathrm{ml}$, hence a defibrination syndrome was suspected. Late in May, the patient had tarry stools and continued to show reduced sedimentation rates. On June 2, examinations of the blood coagulation system were performed on this patient for the first time. In the test for whole blood coagulation time, approximately $1 / 3$ of the volume of a sample formed a soft clot in 5 to $6 \mathrm{~min}$, but the blood was still liquid and failed to coagulate as a whole, thus suggesting probable hypofibrinogene- 
TABLE 3. Laboratory findings

\begin{tabular}{|c|c|c|c|c|c|c|c|c|c|}
\hline \multicolumn{2}{|c|}{ Date } & \multirow{2}{*}{$\frac{\begin{array}{c}\text { C.T. } \\
(\mathrm{min})\end{array}}{5-6}$} & \multirow{2}{*}{$\begin{array}{c}\begin{array}{c}\text { KPTT } \\
(\mathrm{sec})\end{array} \\
64.5 \\
49.5\end{array}$} & \multirow{2}{*}{$\begin{array}{c}\mathrm{PT} \\
(\%) \\
10 \\
26\end{array}$} & \multirow{2}{*}{$\begin{array}{c}\text { TT } \\
(\%)\end{array}$} & \multirow{2}{*}{$\begin{array}{c}\text { II } \\
(\%) \\
82 \\
80\end{array}$} & \multirow{2}{*}{$\begin{array}{c}V \\
(\%) \\
74 \\
55\end{array}$} & \multirow{2}{*}{$\begin{array}{r}\text { VII } \\
(\%) \\
94 \\
100\end{array}$} & \multirow{2}{*}{$\begin{array}{r}\begin{array}{r}\text { VIII } \\
(\%)\end{array} \\
74 \\
66\end{array}$} \\
\hline Jun. & $\begin{array}{l}2 \\
6\end{array}$ & & & & & & & & \\
\hline & 21 & 13 & 39.5 & 57 & 100 & 82 & 72 & 96 & 86 \\
\hline & 26 & & 35.2 & 86 & 100 & 93 & 89 & 100 & 78 \\
\hline Jul. & 1 & & 45.1 & 18 & 100 & 83 & 84 & 100 & 49 \\
\hline & $\begin{array}{r}4 \\
10 \\
12\end{array}$ & & $\begin{array}{l}35.0 \\
44.8 \\
33.1\end{array}$ & $\begin{array}{l}46 \\
82 \\
82\end{array}$ & $\begin{array}{l}100 \\
100 \\
100\end{array}$ & $\begin{array}{l}83 \\
80\end{array}$ & $\begin{array}{l}52 \\
80\end{array}$ & $\begin{array}{l}100 \\
100\end{array}$ & $\begin{array}{l}100 \\
100\end{array}$ \\
\hline & 18 & & 32.6 & 93 & 100 & 78 & 100 & 100 & 100 \\
\hline & $\begin{array}{l}25 \\
31\end{array}$ & & $\begin{array}{l}33.2 \\
33.8\end{array}$ & $\begin{array}{l}93 \\
75\end{array}$ & $\begin{array}{l}100 \\
100\end{array}$ & $\begin{array}{l}95 \\
74\end{array}$ & $\begin{array}{l}80 \\
70\end{array}$ & $\begin{array}{l}100 \\
100\end{array}$ & $\begin{array}{l}100 \\
100\end{array}$ \\
\hline Aug. & $\begin{array}{r}7 \\
26\end{array}$ & & $\begin{array}{l}34.4 \\
39.2\end{array}$ & $\begin{array}{l}70 \\
71\end{array}$ & $\begin{array}{l}100 \\
100\end{array}$ & $\begin{array}{l}87 \\
78\end{array}$ & $\begin{array}{l}80 \\
74\end{array}$ & $\begin{array}{l}100 \\
100\end{array}$ & $\begin{array}{l}100 \\
100\end{array}$ \\
\hline Sep. & $\begin{array}{r}4 \\
14 \\
19\end{array}$ & & $\begin{array}{l}40.1 \\
37.9 \\
39.1\end{array}$ & $\begin{array}{l}57 \\
60 \\
52\end{array}$ & $\begin{array}{l}100 \\
100 \\
100\end{array}$ & $\begin{array}{l}51 \\
65\end{array}$ & $\begin{array}{r}100 \\
76\end{array}$ & $\begin{array}{l}100 \\
100\end{array}$ & $\begin{array}{r}80 \\
100\end{array}$ \\
\hline
\end{tabular}

TABLE 4. Laboratory findings

\begin{tabular}{|c|c|c|c|c|c|c|c|c|}
\hline Date & $\begin{array}{l}\text { C.T. } \\
(\min )\end{array}$ & \multirow{2}{*}{$\begin{array}{c}\begin{array}{c}\text { KPTT } \\
(\mathrm{sec})\end{array} \\
39.1\end{array}$} & \multirow{2}{*}{$\begin{array}{c}\mathrm{PT} \\
(\%)\end{array}$} & \multirow{2}{*}{$\begin{array}{c}\begin{array}{c}\mathrm{TT} \\
(\%)\end{array} \\
100\end{array}$} & \multirow{2}{*}{$\begin{array}{r}\begin{array}{c}\text { II } \\
(\%)\end{array} \\
54\end{array}$} & \multirow{2}{*}{$\begin{array}{c}\begin{array}{l}V \\
(\%)\end{array} \\
80\end{array}$} & \multirow{2}{*}{$\begin{array}{r}\text { VII } \\
(\%)\end{array}$} & \multirow{2}{*}{$\begin{array}{c}\begin{array}{c}\text { VIII } \\
(\%)\end{array} \\
100\end{array}$} \\
\hline Set. 1 & & & & & & & & \\
\hline 2 & & 39.5 & 78 & 100 & 53 & 100 & 100 & 100 \\
\hline 2 & & 35.5 & 84 & 100 & 100 & 100 & 100 & 100 \\
\hline Oct. 1 & & 29.0 & 94 & 100 & 100 & 100 & 100 & 100 \\
\hline 3 & & 31.3 & 95 & 100 & 100 & 100 & 100 & \\
\hline Nov. 1 & & 35.6 & 91 & 100 & 100 & 100 & 100 & 95 \\
\hline 2 & & 42.0 & 24 & 100 & 71 & 90 & 100 & 115 \\
\hline 2 & & 46.1 & 21 & 100 & 45 & 38 & 100 & 100 \\
\hline Dec. & 16.5 & 50.9 & 20 & 100 & 62 & 54 & 100 & 100 \\
\hline 1 & & 69.5 & 25 & 45 & 57 & 45 & 100 & 68 \\
\hline 1 & & 97.2 & 24 & 37 & 77 & 45 & 72 & 70 \\
\hline 2 & & 80.0 & 24 & 37 & 59 & 64 & 100 & 100 \\
\hline 2 & & 58.7 & 62 & 57 & 68 & 82 & 100 & 100 \\
\hline 2 & & 33.5 & 89 & 86 & 90 & 100 & 100 & 100 \\
\hline Jan. & & 29.9 & 89 & 64 & 100 & 100 & 100 & 100 \\
\hline 2 & & 27.2 & 95 & 100 & & & & 100 \\
\hline
\end{tabular}

Table 5. Thrombin time (sec)

\begin{tabular}{|c|c|c|c|}
\hline \multirow{2}{*}{ Material } & \multicolumn{3}{|c|}{ Incubation time } \\
\hline & Immed. & $10 \mathrm{~min}$ & $30 \mathrm{~min}$ \\
\hline Control & 19.0 & 23.8 & 43.3 \\
\hline $\begin{array}{l}\text { Control }+ \text { nonheated patient } \\
\text { plasma }\end{array}$ & 21.7 & 25.8 & 50.7 \\
\hline Control + heated patient plasma & 22.3 & 34.2 & 51.1 \\
\hline Control + heated normal plasma & 23.8 & 26.0 & 27.2 \\
\hline
\end{tabular}


for blood coagulability (1)

\begin{tabular}{|c|c|c|c|c|c|c|c|c|}
\hline$\underset{(\%)}{\operatorname{IX}}$ & $\underset{(\%)}{X}$ & $\begin{array}{l}\mathrm{XI} \\
(\%)\end{array}$ & $\begin{array}{l}\text { XII } \\
(\%)\end{array}$ & $\begin{array}{c}\mathrm{Fbg} \\
(\mathrm{mg} / 100 \mathrm{ml})\end{array}$ & $\begin{array}{l}\text { STT } \\
(\mathrm{sec})\end{array}$ & $\begin{array}{c}\text { PLG } \\
(\%)\end{array}$ & $\begin{array}{c}\text { FDP } \\
(\mathrm{mg} / 100 \mathrm{ml})\end{array}$ & $\begin{array}{l}\text { Plt.c. } \\
\left(\times 10^{4}\right)\end{array}$ \\
\hline $\begin{array}{r}100 \\
56\end{array}$ & $\begin{array}{l}87 \\
86\end{array}$ & $\begin{array}{l}88 \\
55\end{array}$ & $\begin{array}{l}92 \\
66\end{array}$ & $\begin{array}{r}6.0 \\
28.2\end{array}$ & & 89.6 & $\begin{array}{l}80 \\
80\end{array}$ & \\
\hline 100 & 98 & & & & $\begin{array}{c}38.0 \\
(16.6)\end{array}$ & 76.4 & & 6.5 \\
\hline 84 & 100 & & & 73.5 & & 81.1 & & 8.6 \\
\hline 62 & 100 & 84 & 100 & 25.0 & $\begin{array}{c}84.9 \\
(20.1)\end{array}$ & & 80 & \\
\hline 100 & 100 & 100 & 84 & $\begin{array}{l}48.4 \\
98.4\end{array}$ & & & & 54.9 \\
\hline 100 & 100 & 100 & 76 & 81.3 & 46.0 & & 160 & 14.6 \\
\hline 100 & 100 & 100 & 72 & 134.8 & $\begin{array}{c}25.0 \\
(16.3)\end{array}$ & & 40 & 14.7 \\
\hline $\begin{array}{l}100 \\
100\end{array}$ & $\begin{array}{r}94 \\
100\end{array}$ & $\begin{array}{l}100 \\
100\end{array}$ & $\begin{array}{l}60 \\
70\end{array}$ & $\begin{array}{r}125.0 \\
75.0\end{array}$ & & 97.8 & 160 & $\begin{array}{r}11.8 \\
6.1\end{array}$ \\
\hline 100 & 100 & 100 & 76 & 81.3 & & & 80 & \\
\hline 100 & 94 & 90 & 62 & 64.1 & & & & 12.9 \\
\hline 100 & 69 & & & & & & & 10.1 \\
\hline 100 & 86 & 84 & 71 & $\begin{array}{l}53.5 \\
65.6\end{array}$ & & & 80 & \\
\hline
\end{tabular}

\begin{tabular}{|c|c|c|c|c|c|c|c|c|}
\hline$\underset{(\%)}{\text { IX }}$ & $\underset{(\%)}{X}$ & $\begin{array}{c}\mathrm{XI} \\
(\%)\end{array}$ & $\begin{array}{l}\text { XII } \\
(\%)\end{array}$ & $\underset{(\mathrm{mg} / 100 \mathrm{ml})}{\mathrm{Fbg}}$ & $\begin{array}{l}\text { STT } \\
\text { (sec) }\end{array}$ & $\begin{array}{l}\text { PLG } \\
(\%)\end{array}$ & $\begin{array}{c}\text { FDP } \\
(\mathrm{mg} / 100 \mathrm{ml})\end{array}$ & $\begin{array}{l}\text { Plt.c } \\
\left(\times 10^{4}\right\rangle\end{array}$ \\
\hline 100 & 67 & 52 & 49 & 59.0 & & 93.3 & 80 & 14.1 \\
\hline 86 & 74 & 52 & 41 & 71.0 & & 94.7 & 80 & \\
\hline 57 & 100 & 56 & 44 & 112.0 & & 97.8 & 80 & 13.6 \\
\hline \multirow[t]{2}{*}{100} & 100 & 87 & 54 & 218.0 & & 107.6 & & 21.5 \\
\hline & 100 & & & 134.0 & 20.1 & & & 13.8 \\
\hline 59 & 57 & 52 & 31 & 124.0 & 30.3 & & & 14.8 \\
\hline 100 & 57 & 56 & 59 & 59.0 & 100.5 & 83.1 & 40 & 13.2 \\
\hline 72 & 47 & 41 & 34 & 30.8 & 90.8 & & & 7.1 \\
\hline 76 & 70 & 53 & 100 & 31.2 & 95.5 & & & \\
\hline 37 & 25 & 24 & 57 & 41. 2 & no clot & & & 15.6 \\
\hline 52 & 38 & 20 & 20 & 100.8 & "I & & & 2.8 \\
\hline 70 & 50 & 29 & 51 & 86.0 & " & & & \\
\hline 98 & 74 & 35 & 86 & 104.8 & & & & 3.4 \\
\hline 100 & 100 & 68 & 100 & 132.0 & 40.5 & & & \\
\hline 100 & & 77 & 60 & 204.0 & 20.6 & & & 40.9 \\
\hline 100 & & 77 & 88 & 200.0 & 24.3 & & & 31.7 \\
\hline
\end{tabular}

mia. The soft clot began dissolving rapidly about 15 min later and became smaller to a size of about a half rice grain at 30 to $60 \mathrm{~min}$. These findings indicated the presence of enhanced fibrinolytic activity concomitant with hypofibrinogenemia.

Laboratory findings for blood coagulability (Tables 3, 4 and 5). As shown in Table 3, the first screening tests for blood coagulability revealed a marked prolongation of the kaolin partial thromboplastin time (KPTT), a conspicuously decreased activity in the one-stage prothrombin time $(\mathrm{PT})$, and, in spite of them, a significant shortening in the plasma thrombotest (TT) value. In both the KPTT 
and PT, the plasma sample failed to coagulate as a whole; and the clot formed was seen only as a fibrin network as in the whole blood coagulation time test, besides the prolonged coagulation time. These were considered to indicate hypofibrinogenemia. The plasma Fbg level was extremely lowered, $6 \mathrm{mg} / 100 \mathrm{ml}$. Coagulation factors II, V and VIII showed slightly diminished activities, while the remaining clotting factors showed no significant changes. A slight decrease of plasminogen (PLG) with increased fibrin or fibrinogen degradation products (FDP) was also found. As shown in Table 5, tests were conducted to determine whether the prolonged thrombin time (Thr-T) was due to a fibrin degradation product or to a fibrinogen degradation product. Incubated mixtures with equal amounts of patient's plasma and normal plasma all showed a significant prolongation of Thr-T, and this trend was particularly marked with mixtures containing the patient's plasma that had been heated at $56^{\circ} \mathrm{C}$ for $10 \mathrm{~min}$. Then, it was considered that the prolonged thrombin time was due primarily to the antithrombin action of fibrin degradation products or, in other words, that the intravascular clotting took place at first and the degradation products yielded the antithrombin action.

Subsequent clinical course (Figs. 3 and 4). The defibrination with a plasma Fbg value of $6 \mathrm{mg} / 100 \mathrm{ml}$ was most remarkable on June 2 and enhanced hemorrhagic manifestations such as tarry stools, etc. were evident. The patient had blood transfusions ( $2,000 \mathrm{ml}$ in 4 consecutive days) and intravenous injection of heparin in a dose of $0.5 \mathrm{mg} / \mathrm{kg} /$ day. The plasma Fbg concentration began to increase gradually to $73.5 \mathrm{mg} / 100 \mathrm{ml}$ on June 26 , when the improvement in the KPTT and PT became evident. Early in July, she again started to show positive occult blood in stools and a marked diminution of plasma Fbg-level to $25 \mathrm{mg} /$ $100 \mathrm{ml}$; therefore, administration of heparin was reinstituted on July 10 at a dosage level of $0.5 \mathrm{mg} / \mathrm{kg}$. The plasma Fbg concentration rose progressively to a value of $134.8 \mathrm{mg} / 100 \mathrm{ml}$ on July 18 , with a subsequent gradual decline. These changes in blood coagulability coincided well with patient's clinical manifestations of hemorrhagic tendency. In view of the relatively stabilized plasma Fbg level and insignificant efficacy of fever, the dosage of prednisolone therapy was gradually reduced in September eventually to a level of $30 \mathrm{mg} / \mathrm{day}$. In the middle of September, she developed epistaxis and a bleeding tendency after a subcutaneous or intramuscular injection and began to complain of pain and slight swelling especially in the left lower limb with the finding of diminished pulsation of the left dorsalis pedis artery. The condition, therefore, was interpreted as development of thrombosis due to relapse of consumption coagulopathy and heparin therapy was started on a full scale. Four intravenous doses of regular heparin, $0.5 \mathrm{mg} / \mathrm{kg}$ were given on the first day. The pain was relieved following injection and recurred again in 5 to $6 \mathrm{hr}$. The pain was almost completely gone on the second day and the intravenous administration of regular heparin was replaced with a long-acting heparin preparation (Heparin Lente). It was given $0.5 \mathrm{mg} / \mathrm{kg}$ b.i.d. intramuscularly in order to reduce the number of injections. 
However, a fairly extensive ecchymosis occurred at the site of injection, which affected her psychologically to a great extent; and the long-acting intramuscular heparin was displaced with intravenous regular heparin which, thereafter, was continued at a dose level of $0.25 \mathrm{mg} / \mathrm{kg}$ b.i.d. partly at the patient's strong request. The plasma Fbg showed a gradual elevation and reached a practically normal level of $218 \mathrm{mg} / 100 \mathrm{ml}$ on October 17 . Clinically, she became gradually afebrile and relieved of the hemorrhagic tendency, thereby exhibiting an entirely favorable course from about late in September till early in November. At about the beginning of November, she developed subcutaneous indurations in the left leg and fever. The plasma Fbg was again reduced and a tendency to exacerbation of abnormalities in the blood coagulation tests occurred. At this stage, a bleeding was noted in the anal region. The dosage of prednisolone was increased from $30 \mathrm{mg} /$ day to a level of $60 \mathrm{mg} /$ day and that of intravenous heparin therapy to $0.5 \mathrm{mg} / \mathrm{kg}$ b.i.d. On November 27 , the bulbar conjunctiva was noted to be slightly jaundiced and at the same time, a hemorrhagic tendency, such as uncontrolable post-injection bleeding as well as rebleeding at the site of injections given the previous day, again appeared. The icterus was progressively pronounced during the latter half of December, and the plasma Fbg level fell drastically to $30-40 \mathrm{mg} / 100 \mathrm{ml}$ from the end of November toward early in December. Because of this and of a marked decrease of other coagulation factors, the dosage of intravenous administration of heparin was increased to $20 \mathrm{mg}(0.5$ $\mathrm{mg} / \mathrm{kg}$ b.i.d. hence $80 \mathrm{mg} /$ day) on December 6 along with institution of $\mathrm{Fbg}$ at $2 \mathrm{mg} /$ day and PPSB-Nichiyaku (a concentrated mixture of factors II, VII, IX and $\mathrm{X}$, Nihon-Seiyaku) at 2 vails per day for 5 consecutive days. On December 17, she became totally unconscious for a time following the third intravenous injection of heparin, suggesting the occurrence of cerebral thrombosis or hemorrhage. An additional vial of PPSB, $2 \mathrm{~g}$ of Fbg and transfusion of bank blood were undertaken immediately, and normal consciousness was restoled in several hours. Subsequently, because of these treatments, the icterus gradually subsided, and the plasma Fbg concentration returned to practically within normal limits, $200 \mathrm{mg} /$ $100 \mathrm{ml}$, late in January. The patient has since been in a well-controlled state both symptomatically and in respect of blood coagulation.

Changes of blood coagulation tests (Tables 3 and 4). As shown in Tables 3 and 4, the KTPP, PT, serial thrombin time (STT; determined by using 5 units $/ \mathrm{ml}$ of thrombin), platelet count, PLG and FDP all showed changes in correlation with the elevation or decline of the plasma Fbg. On October 17, the plasma Fbg was $218 \mathrm{mg} / 100 \mathrm{ml}$, the platelet count $21.5 \times 10^{4} / \mathrm{mm}^{3}$, KPTT $29.0 \mathrm{sec}$, PT $94 \%$, and TT slightly prolonged, respectively; thus all these parameters showed virtual normal values. From the beginning of November the patient was febrile with the development of newly formed lesions and, at practically the same time, showed lowered plasma Fbg levels, prolonged KPTT, PT and STT and decreased plasma PLG and platelet count, which again altogether improved in response to increased dosages of intravenous administration of heparin and of corticosteroid. 


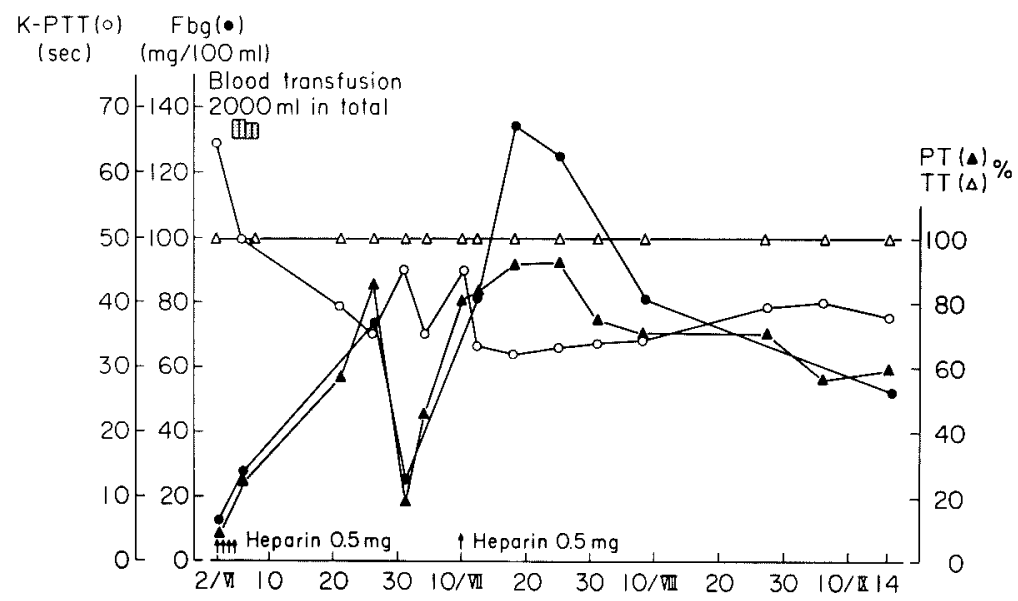

Fig. 5. Changes in K-PTT, PT, TT and fibrinogen content (1).

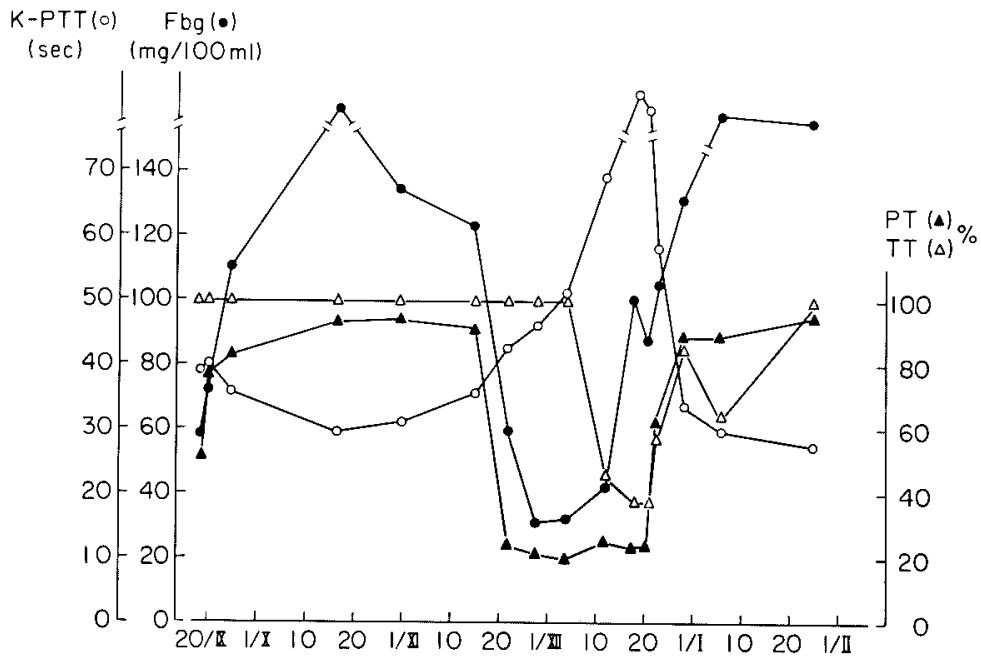

Fig. 6. Changes in K-PTT, PT, TT and Fibrinogen content (2).

Almost with the development of jaundice at the end of November, the Fbg content and other activities of plasma coagulation factors were decreased. It was of profound interest that a marked fall of activity of TT was evident at this stage for the first time. As for interrelations between the plasma Fbg level and the KPTT, PT and TT (Figs. 5 and 6), the clotting time of plasma TT which had been consistently reduced showing activities over $100 \%$ (30 sec approx., $100 \%=40 \mathrm{sec}$ ) returned to a normal value of about 40 sec. during remissions. The plasma Fbg level was restored to normal in response to heaprin therapy, and there was a corresponding shortening in KPTT and elevation of PT activity. As seen from Fig. 6 showing the pertinent clinical data following the initiation of heparin 

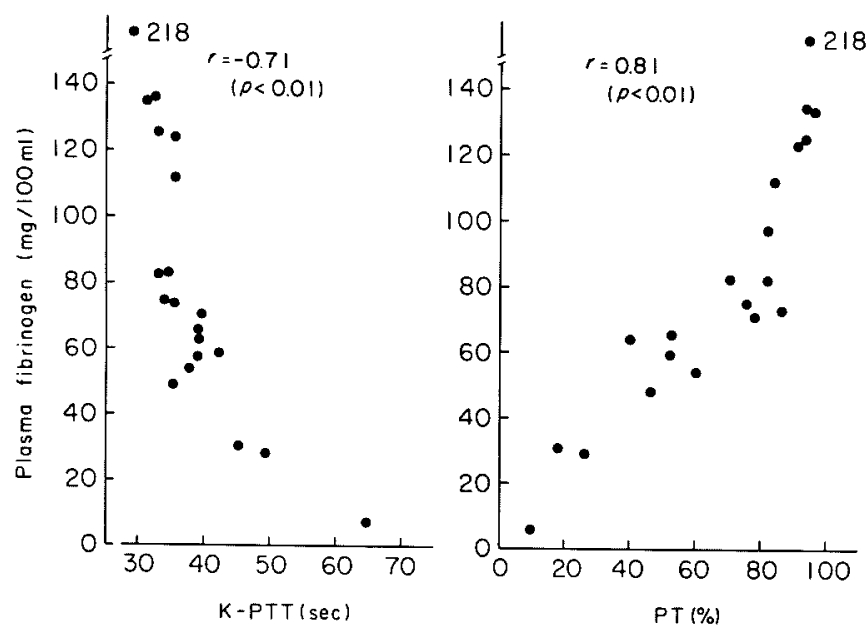

Fig. 7. Correlations between K-PTT, PT, and plasma fibrinogen content.

therapy on a full scale (daily), a substantial elevation of plasma Fbg and an associated improvement in blood coagulability occurred. In the middle of November, reaggravation with advancing illness was manifested by newly formed subcutaneous indurations, hepatic enlargement, and jaundice, which were again essentially relieved by increased dosage of heparin, administration of Fbg and PPSB, and blood transfusion. During this phase the plasma Fbg value showed highly significant correlations with the KPTT and PT activities $(r=-0.71$ and 0.81 respectively, at $p<0.01$ ) (Fig. 7).

\section{Discussion}

Weber-Christian disease was first reported in 1892 by a German physician, Victor Pfeifer (1892) who described a case of a 23-year-old woman with febrile multiple atrophy of subcutaneous adipose tissues in a paper; "Ueber einen Fall von herdweiser Atrophie des subcutanen Fettgewebes". Yokoyama and Hatano (1951) reported a case of this condition in Japan for the first time, in 1951 as "Dermatomyositis complicated with Weber-Christian disease". A total of approximately 150 cases had since been reported in this country till the end of the last year. In the year of 1925, Weber (1925) described a case of a 50-year-old woman with "relapsing nonsuppurative nodular panniculitis", and subsequently in 1928, a case of a 25-year-old woman with a similar clinical course was reported by Christian (1928) under the designation: "relapsing febrile nodular nonsuppurative panniculitis", thus the term "febrile" depicting another characteristic of the condition being added. The condition has been referred ever since to as Weber-Christian disease, Pfeifer-Weber-Christian disease or the above-described designations named by Weber and Christian.

The nature and clear definition of this condition has been still unsettled. Milner and Michinson (1965) have applied Weber-Christian panniculitis to a 
condition characterized by pathologic changes only limited to the subcutaneous adipose tissue, and systemic Weber-Christian disease to that in which the pathologic changes involve the adipose tissues of various organs throughout the body. Nishiyama (1970) has defined the condition as one in which the adipose tissues of the whole body are systematically affected by unknown cause among diseases characterized principally by lipolysis of the fat tissue. Namely, according to Nishiyama, it falls under the category of mesenchymopathy in the broad sense, hence a disease similar to the so-called collagen diseases.

The patient in this report was admitted to this University Hosptial early in February, 1972, because of subcutaneous induration on the medial surface of the right thigh. Nosebleeding and ecchymosis became evident at the end of April at which time the plasma Fbg level was found to be as low as $51 \mathrm{mg} / 100 \mathrm{ml}$. Late in May tarry stools were noted and the case was diagnosed as consumption coaglopathy in view of the above described findings in the blood coagulation tests including the evidence of marked hypofibrinogenemia. Corticosteroid therapy and various attempts at hemostatic control were undertaken with consequent improvement of the blood coagulation abnormalities. These included a hemorrhagic tendency that developed due to complex abnormalities in blood coagulation including diminished activity of coagulation factors and enhanced fibrinolytic activity of the plasma arising from hepatic dysfunction associated with jaundice and liver enlargement. All of these abnormalities returned to normal, and the patient had since been in a good, stable condition up to September, 1973, over a year after the onset of illness.

There are many reports describing the presence of a hemorrhagic tendency in this disease. Ino and Suzuki (1969) have accumulated 48 typical cases of Weber-Christian disease with systemic panniculitis among 120 cases of this disease reported up to 1969 in Japan, and reported that fever and subcutaneous induration were present in all cases, enlargement of the liver in $56.2 \%$ (27 cases), and a hemorrhagic tendency being also frequent, $35.4 \%$ (17 cases). They have described that diminished platelet count and plasma $\mathrm{Fbg}$ with prolonged bleeding time were noted in one case and also prolonged PT in another case, and mentioned that gastrointestinal bleeding due to abnormalities in blood coagulation is a main cause of death in advanced cases. Although they have stressed the importance of investigation on the underlying mechanism of bleeding, there are as yet extremely few reports concerning the essential nature of bleeding in this disease.

of particular interest would be the mechanism which might cause the development of consumption coagulopathy. The lipid metabolism in WeberChristian disease, which affects the adipose tissues of the whole body, is also of interest and the presence of hyperlipemia in this disease is widely recognized. In our case, a slight to moderate degree of serum lipid elevation was noted. Triglyceride was 150 to $300 \mathrm{mg} / 100 \mathrm{ml}$, phospholipid was 250 to $300 \mathrm{mg} / 100 \mathrm{ml}$, and total cholesterol was 200 to $300 \mathrm{mg} / 100 \mathrm{ml}$ during June through July when she showed marked changes in blood coagulation factors with a pronounced fall of 
plasma Fbg on transfer to this clinic. However, the values of plasma free fatty acid were very low during this period, that is, $151 \mu \mathrm{Eq} /$ liter on June 3, $353 \mu \mathrm{Eq}$ / liter on June $6,84 \mu \mathrm{Eq} /$ liter on July $10,42 \mu \mathrm{Eq} /$ liter on July 18 and $76 \mu \mathrm{Eq} /$ liter on July 31. No other drugs which might affect lipid metabolism, except for corticosteroids, were given during this period. Meanwhile, plasma free fatty acid and triglyceride, in particular, showed a marked increase (1,500 to 3,000 $\mu \mathrm{Eq} /$ liter and 600 to $1,300 \mathrm{mg} / 100 \mathrm{ml}$, respectively) from September onward following initiation of heparin therapy and increase of corticosteroid. Plasma electrophoretic analysis demonstrated type IV hyperlipemia with marked increase of pre- $\beta$ lipoprotein. The development of jaundice and hepatic enlargement with exacerbation of liver function disturbance at this stage suggested development of fatty liver. That is, it would be reasonable to assume that excess amounts of plasma free fatty acid enter the liver to cause fatty liver and hypertriglyceridemia. Hypertriglyceridemia can arise from a disturbance in the mechanism of elimination of neutral fat from the blood, but this possibility may be ruled out in this case because she showed a normal plasma lipoprotein lipase activity level of $9.08 \mu \mathrm{Eq} /$ $\mathrm{FFA} / \mathrm{ml} / \mathrm{hr}$ at the most after an intravenous administration of heparin (Fig. 8). The above-described enhanced neutral fat synthesis in the liver is considered to be a probable cause in the pathognesis of hypertriglyceridemia of this patient.

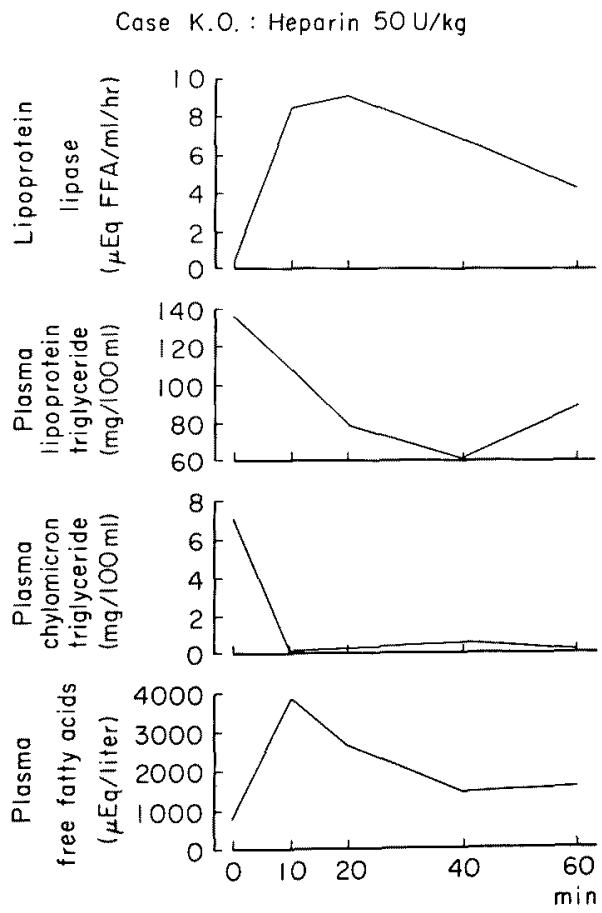

Fig. 8. Changes in lipoprotein lipase activity and plasma lipid levels after i.v. heparin injection. 
From these findings, the abnormality in lipid metabolism of the patient would, therefore, be summarized to the following two features: 1) Abnormally low plasma free fatty acid levels during the unstable phase of the underlying disease with pronounced abnormality in blood coagulability; 2) Remarkable increase of plasma free fatty acid with hypertriglyceridemia and fatty liver during the relatively stable phase of the disease with controlled blood coagulation abnormalities following dosage increase of steıoid and institution of heparin therapy.

Plasma free fatty acid is derived from adipose tissues, and, therefore, decrease in their plasma content suggests systemic abnormalities of adipose tissues. Namely, there is a possibility that, in patients with Weber-Christian disease, liberation of fatty acids from adipose tissues is inhibited through some unknown mechanism, and this represents an essential aspect of the disease. That the low level of free fatty acid shows significant correlation with blood coagulability, especially the plasma Fbg level, is a feature of profound interest from the standpoint of hemorrhagic diathesis, although it cannot be simply interpreted. As an explanation of the abnormally lowered plasma free fatty acid, it also seems to be conceivable that, conversely, free atty acid as well as other plasma factors as Fbg dissipate during the phase of active consumption, and they rise during the phase of stabilization. It is also probable that administration of heparin and dosage increase of steroid both have a direct relation to the elevation of plasma free fatty acid during remission.

Lipids hasten blood coagulation and consequently, fat-rich diet gives rise to a state of enhanced blood coagulability. Further, it is also known that intravascular infusion of fat causes an intravascular coagulation syndrome. Thus, the one which serves as a trigger for consumption coagulopathy is long-chain saturated fatty acids which are capable of activating contact factors and of aggregating platelets. Evidence has been shown that stearic acid injected into rabbits produced activation of contact factor as well as consumption of coagulation factors and platelets, proving even singly to be a trigger (Matsuoka and Watanabe 1970).

Besides hyperlipemia due to abnormal lipid metabolism, we would like to point out systemic histological changes - especially those of the vascular wall - as factors which might act as a trigger for consumption coagulopathy. While the importance of altered properties of vascular wall has been stressed in the pathogenesis of thromobosis since the classical studies of Virchow, histologic changes in patients with Weber-Christian disease may be classified into three stages: (1) acute inflammatory stage, (2) stage of necrosis and lipophagia (presenting the microscopic features of lipogranuloma) and (3) fibrosis, as described by Bailey (1937) and Lever (1964). According to Sato and Akai (1965), the histologic changes in the first stage consist of localized edema and necrosis of the subcutaneous adipose tissue with neutrophil leukocytic infiltration among fat cells with occasional nuclear debris. In this phase of the disease, edema, dilatation of capillary vessels, and nonspecific inflammatory infiltrations are frequently seen not only in the subcutaneous adipose tissue but in the corium, especially below the 
middle layer, that is, angitis (Iijima et al. 1959; Shiokawa and Horie 1961) or fibrinoid degeneration of the vascular walls (Sano et al. 1959) and also fibrinoid degeneration of the connective tissue (Tanimura et al. 1954). It has been stated that these pathological changes found in the primary stage represent the essential nature of Weber-Christian disease, while those of the second (lipophagia) and third (fibrosis) stages should be regarded as secondary to those of the first stage. There are many reports to describe the presence of angitis in Weber-Christian disease. Takahashi et al. (1965) reported that there was microscopic evidence of significant changes in the walls of veins in adipose tissue in an autopsy case of Weber-Christian disease. Namely, venous lumen was dilated with degeneration or loss of lining endothelial cells, and the collagen fibers constituting the venous wall were sparse and showed metachromasia. These are characteristic features of the so-called fibrinoid degeneration or panphlebitis. Such vascular changes associated with increased fibrin deposition were demonstrable in 8 of 10 cases. Takahashi et al. (1965) have concluded that these vascular alterations represent one of the pathologic changes essential to Weber-Christian disease from the relation to the clinical course, independent to steroid therepy.

It may be probable that these changes and destruction of the vascular wall eventually liberate tissue thromboplastin into the circulating blood as well as active blood contact factors causing increased ability of platelet adhesiveness and aggregation with consequent enhancement of blood coagulability, which, in turn, brings about thrombosis and consumption coagulopathy. In addition, abnormalities in the peripheral blood circulation, hypofunction of the reticuloendothelial system, abnormalities in the fibrinolytic system and so forth may also take part in the pathogenetic mechanism whereby thrombosis and consumption coagulopathy develop. In our case, a chronic course of consumption coagulopathy was observed, and this also depicts clinically the essential nature of the disease.

Manifestations of hemorrhagic diathesis are seen with high frequency in Weber-Christian disease as pointed out by Ino and Suzuki (1969) as well as many other investigators. However, reports of blood coagulation studies on hemorrhagic diathesis in this disease as yet are extremely few.

Three consecutive examinations of the blood coagulation system conducted in 4 months by Yoshioka et al. (1959) on a 16-year-old female patient who eventually died of Weber-Christian disease about 6 months after onset revealed the thrombocytopenia due to a disturbed hematopoietic function of the bone marrow secondary to spread of pathologic changes and other alterations in the blood coagulation system due to liver damage respectively, but there were no descriptions of findings concerning changes in the terminal stage.

In our case, an extremely lowered plasma Fbg level and a marked prolongation of KPTT and PT, yet with increased plasma TT values (over 100\%), were observed initially at the height of the disease along with slight to moderate diminutions of coagulation factors II, V, and VIII, increased FDP, a slight decrease of PLG and thrombocytopenia. With progressive improvement, the KPTT, PT, 
and the various coagulation factors became normalized. Plasma TT almost consistently showed activities over $100 \%$ and showed a tendency to normalization with prolongation to a level of approx. $40 \mathrm{sec}$ as symptomatic remissions occurred. The TT activity fell proportionately with vitamin K-dependent coagulation factors only at the height of jaundice and liver enlargement with pronounced hepatic dysfunction.

of marked interest, besides these changes in the blood coagulation system, is that the erythrocyte sedimentation rate was increased in the very early stage where pathologic changes were limited to the subcutaneous adipose tissue with no manifestations of hemorrhage, whereas it showed a trend to normalization or retardation during exacerbation of the patient's general condition with overt bleeding. These changes have been reported also by other groups of investigators (Hori et al. 1959; Iino and Suzuki 1969) but no definite explanation was made as yet, however. Serious hemorrhagic manifestations due to complicating consumption coagulopathy seem to be frequent in cases of Weber-Christian disease, or at least advanced cases of systemic involvement, and the changes in the plasma Fbg concentration in particular are considered to be an important factor which influence the erythrocyte sedimentation rate. That is, according to Yamagata et al. (1968), since the sedimentation rate is delayed and shows a trend toward normalization in response to transfusion of Fbg in all cases of congenital afibrinogenemia, then the delayed sedimentation rate, being apparently normalized in consequence of the development of hypofibrinogenemia due to consumption coagulopathy contrary to the graveness of the condition, perhaps contributed to the diagnostic misjudgement by the clinicians in advanced cases of Weber-Christian disease. It seems that the presence of a hemorrhagic diathesis with decreased erythrocyte sedimentation rate, even in previously reported cases unexamined for blood coagulability, suggest complication of the disease with consumption coagulopathy from the close consistent correlations of plasma Fbg level and sedimentation rate.

\section{References}

1) Bailey, R.J. (1937) Relapsing febrile nodular nonsuppurative panniculitis (WeberChristian disease). J. Amer. Med. Ass., 109, 1419-1425.

2) Christian, H.A. (1928) Relapsing febrile nodular nonsuppurative panniculitis. Arch. Int. Med., 42, 338-351.

3) Hori, T., Araki, T. \& Idemura, K. (1959) Weber-Christian disease. Acta Med. Niigata, 72, 872-877.

4) Iino, S. \& Suzuki, H. (1969) Weber-Christian disease. Saishin Igaku (Jap.), 24, 1767-1773.

5) Iijima, S., Yamagata, A. \& Kitamura, S. (1959) Clinical aspects and pathology of Weber-Christian disease. Saishin Igaku (Jap.), 14, 762-776.

6) Lever, W.F. (1964) Histopathology of the Skin, 4th Ed., Philadelphia, Lippincott, p. 247.

7) Matsuoka, M. \& Watanabe, T. (1970) Intravascular coagulation syndrome - Primarily with reference to the condition in internal medicine. Ketsueki to Myakkan (Jap.), 1, 5-26. 
8) Milner, R.D.G. \& Michinson, M.J. (1965) Systemic Weber-Christian disease, $J$. Clin. Path., 18, 150-156.

9) Nishiyama, S (1970) Weber-Christian disease - Its conception and histologic etiology. Naika (Jap.), 25, 858-864.

10) Pfeifer, V (1892) Ueber einen Fall von herdweiser Atrophie des subcutanen Fettgewebes, Deutch. Arch. Klin. Med., 50, 438-449.

11) Sano, E., Ueda, U., Miyazaki, Y., Ohishi, Y. \& Shimoda, D. (1959) An autopsy case of Weber-Christian disease. Folia Dermatol. Jap., 69, 355-375.

12) Sato, Y. \& Akai, A. (1965) Clinical aspects and pathology of Weber-Christian disease-a review and discussion primarily of cases reproted in Japan. HifuRinsho (Jap.), 7, 230-241.

13) Shiokawa, Y. \& Horie, M. (1961) A case of Weber-Christian disease. Rinsho Naika Shonika (Jap.), 16, 1257-1260.

14) Takahashi, S., Sasai, Y., Kasai, T., Sato, A., Saito, S., Suwa, N., Sasano, N., Watanuki, T., Fukuda, T. \& Ohsato, Y. (1965) A case of Weber-Christian disease dying from intracerebral and intraventricular hemorrhage. Saishin-Igaku (Jap.), 20, 2847-2857.

15) Tanimura, T., Yoshino, K., Sonoda, R. \& Taguchi, T. (1954) Weber-Christian disease. Hifu to Hinyoki (Jap.), 16, 1-4.

16) Weber, F.P. (1925) Relapsing nonsuppurative nodular panniculitis. Brit. J. Dermat., 37, 301-311.

17) Yamagata, S., Mori, K., Kayaba, T., Hiratsuka, I., Ishimori, A., Tozawa, T., Matsuyama, K., Takahashi, O. \& Toyohara, M. (1968) A case of congenital afibrinogenemia and review of reported cases in Japan. Tohoku $J$. exp. Med., 96, 15-35.

18) Yokoyama, H. \& Hatano, S. (1951) Dermatomyositis complicated with WeberChristian disease. Rinsho-Hifu (Jap.), 5, 512-517.

19) Yoshioka, K., Fukui, H., Tagawa, T., Iida, M., Fukuoka, Y., Ito, N. \& Takeda, T. (1959) An autopsy case of Weber-Christian disease associated with pancytopenia and abnormalities of some clotting factors. Saishin-Igaku (Jap.), 14, 3325-3332. 